ACHIM MITTAG AND FRITZ-HEINER MUTSCHLER

\title{
INTRODUCTION: UNIVERSALISM IN ANCIENT CHINA AND ROME
}

In recent years issues of the "Self" and the "Other" have become prominent in philosophical, philological, and cultural studies. By developing common values and norms and by cultivating specific virtues, social, and political communities create, over time, a communal identity, a Collective Self, and consciousness of this Collective Self implies per definition a sense of the Otherness of Others. In most cases, the totality of the values, norms, and virtues shared by the members of a community is increasingly perceived as something that distinguishes them from others, who are often considered not only as different but as inferior. Many cultures, on the other hand, also develop a concept of Humanity-of shared qualities and a common bond between all human beings. If this is the case, the discourse of Humanity is then forced to negotiate, on an ongoing basis, with the discourse of group identity, a process that leads to tensions time and again. Developments on the level of discourse are often related to social and political developments within and between the communities or groups under question. The analysis of these phenomena has advanced our understanding of the histories of particular societies and polities and at the same time of the functioning of human societies and polities in general. In the age of Globalization, with states, regions, and cultures interacting in new and increasingly intense ways, this understanding has acquired a new actuality.

It was in the context of these ideas and reflections that a conference with the title "Empires and Humankind: China and the West Compared" was held in Dresden during June 12-15, 2008. The conference was a product of cooperation between two research projects, the project "Humanism in the Age of Globalization" at the Institute for Advanced Study in the Humanities, Essen, directed by Jörn Rüsen, and the project "Roman Values and Roman Literature" at the Collaborative Research Centre "Institutionality and Historicity," Dresden

ACHIM MITTAG, Professor, Department of Chinese and Korean Studies, Tuebingen University. Specialties: Chinese historiography, Chinese classical learning, Chinese intellectual history. E-mail: achim.mittag@uni-tuebingen.de. FRITZ-HEINER MUTSCHLER, Professor, Institut für Klassische Philologie, Technische Universität Dresden. Specialties: Augustan poetry, Roman philosophy, Roman literature and society, Chinese historiography. E-mail: fritz-heiner.mutschler@tu-dresden.de

Journal of Chinese Philosophy 37:4 (December 2010) 522-526

(C) 2010 Journal of Chinese Philosophy 
University, directed by Fritz-Heiner Mutschler. Reflecting and combining the interests of the two projects, the aim of the conference was to examine, from a comparative perspective, how the negotiation between the discourse of identity and the discourse of humanity, developed in ancient China and Rome and how this development was related to broader sociopolitical developments, especially the establishment of "world-empires."

The conference papers were supposed to view these issues from the standpoint of different fields of study: historical and political thinking, theory and practice of law, language and writing, philosophy and religion. The invitation of classicists and sinologists specializing in those fields was to ensure the comparative dimension, the inclusion of scholars from China and the West was to stimulate cross-cultural discussion. On the whole, the conference was intended not just to theorize about interhuman, international, and intercultural understanding, but also to practice it.

We are grateful to the editors of the Journal of Chinese Philosophy for joining us in this cooperative venture-for giving us an opportunity to present a set of three articles that give a sense of the diverse nature of the questions asked and answers proposed at the Dresden conference.

Wolfgang Behr, a specialist in Chinese linguistics, explores the emergence of concepts of "Self" and "Other" at the very root of human existence, on the level of language: Neighbors are perceived as "whacky," in the first place because they speak differently and incomprehensibly—they are "tongue-twisted" ( fan she 反舌). Examining the linguistic situation in the preimperial "sino-sphere" (HuaXia 華夏), however, there is a conspicuous lack of astonishment about "twisted talk" and linguistic diversity. If at all noted, these differences tend to be explained in terms of cultural refinement, education, and "habitual" environments, rather than in terms of ethnicity. Thus, a "western barbarian" (Rong 戎) will speak the Rong language as a grown-up but, when growing up among the Chu 楚 people, he will speak the Chu language. ${ }^{1}$

This idea of language as a socially acquired skill, which is widely found in ancient Chinese texts, contrasts sharply with the Near Eastern and European curiosity in determining a "primeval" or "inborn" language common to all peoples. The early Chinese attitude toward language as a product of man's socialization can be best explained by inferring a widespread bi- and multilingualism throughout the Zhou 周 cultural domain, including the non-Sinitic-speaking peoples who became increasingly incorporated into this domain. This points to an early Chinese language, which must have had extensive linguistic contacts with other language families. Most importantly, this 
language-Old Chinese-was very different, both from its postimperial successors, and from what we have been told about it since the early linguistic inquiries in the wake of the Jesuit China missions.

A veritable breakthrough in the reconstruction of the phonology and morphology of Old Chinese has been achieved in the recent twenty-five years by an international group of linguists. This breakthrough has come to be connected with the "six-vowel" convergence model, which as a basic assumption asserts the differentiation of six simple main vowels. Next there is the discovery of a "sesquisyllabic" (one minor syllable followed by a full one) prosody, resulting in a fairly complex syllable structure. The phonological reconstruction of Old Chinese along these lines has immensely enhanced our understanding of its rich agglutinating morphology, which provided the possibility of encoding grammatical and various other sorts of linguistic information. In sum, it has become evident that Old Chinese contrasts starkly with the post-Qin 秦 Chinese language with its largely "isolated" typology, its tonal system, and its prevalence of disyllabic vocabulary.

What provokes interest in the larger context of our exploration is the observation that this most drastic typological shift of the Chinese language occurred in a long-term process, which was driven by huge social upheavals in the Eastern Zhou (Dong Zhou 東周) period (770256 BCE). It came to completion not until the consolidation of the Han 漢 empire. This shift in the spoken language resulted in the ossification of the "classical" literary language, which under the auspices of the unified empire emerged as a powerful tool of communication. At the same time, we can observe the rise of clear-cut sino-xenic demarcations as part and parcel of a drastic reconceptualization of the "Self" and the "Other." However, in the discourse about the ethnic "Other," language, that is, the "tongue-twistedness" of the barbarians, was only one among a set of identity markers. A much greater impact on determining the boundary between the Chinese realm (Hua 華) and the uncivilized world ( $y i$ 夷) must be accorded to the artificial written language.

Yang Huang, a scholar specializing in Greek history, examines the idea of the barbarian and its role in the construction of Greek selfawareness. Huang's article is related to the above article in the fact that the term barbarian originally denoted those whose language is unintelligible - the ones who "babble" or "stammer." The term makes a distinction between the Greeks and Others on the basis of language. Yet as Yang Huang shows, over time the concept of the "barbarian" as the extreme Other became loaded with semantic components that go beyond language.

This development began already with Homer. The term barbaros, to be sure, does not appear at all in his epics and the term bar- 
barophonos only once; but in presenting a war fought by a coalition of Greeks against an alliance of peoples from the East, Homer imbued the Greeks with an awareness both of themselves and of the Others who were both different and opposed to them. Thus, the idea of Greek identity emerging in Homer was not simply "aggregative," or "constructed from within," as has been suggested, but already, at least in part, "oppositional," that is, "defined from without." Nevertheless, the image of the generic barbarian with all its derogatory traits was here by no means fully developed.

It was the Persian Wars that finally shaped the Greek conception of the barbarian: After the shock of the Persian invasion, the Persians in particular and Asiatics in general were presented and viewed as the archetypical barbarian. This is broadly attested in fifth-century Greek literature, including the Persians of Aeschylus and the Histories of Herodotus, and in contemporary and later Greek arts. Thus an intensifying sense of difference between the Greeks and the barbarians, based largely on ethnocentrism, gave rise to a sharply polarized form of Orientalism whereby the Orient was viewed as the ultimate Greek Other, characterized by properties of despotism, slavishness, and cowardice that distinguished it from Greek democracy, freedom, and courage. In the fourth century вСE these Orientalist ideas were the basis for a new concept of Panhellenism in Greek discourse and for a strategy of expansionism in Greek politics. It was against this ideological background that Alexander the Great launched his expedition to the East.

Achim Mittag, a sinologist, and Fritz-Heiner Mutschler, a classicist, deal with the development of universalistic ideas in the historical thinking of the Chinese and Roman empires, investigating the questions of when "the world" as a larger whole began to play a role in the pertinent sources and how those sources viewed the relationship between the respective polity and the world. The article looks first at the sociopolitical context of historical consciousness and historiography. In China there is, from early on, a strong connection between historiography and the state through the official referred to as shi 史, or "scribe." Despite changing functions in the preimperial period, the "scribe" remains central to Chinese history writing throughout the ages. In Rome a connection between historiography and state exists as well but it manifests itself more loosely: Normally Roman historians are members of the ruling class and thus politically involved or aware but most write their histories after retiring from politics as private citizens, not in an official capacity.

The following sections of the article investigate the presentation of the two polities and their relationship to the surrounding world in 
historical texts. As to the earlier period, a difference between the Chinese and Roman sides can be observed. In China, universalistic ideas such as All-under-Heaven (tianxia 天下) develop early in connection with the sovereign-related doctrine of Heaven's Mandate (tianming 天命). In Roman texts we find, in contrast, a strictly communal orientation that takes the surrounding world into account only in terms of the development of the commonwealth-only as the object of Roman wars and expansion. In comparing the fully developed empires of China and Rome, one observes a broader convergence of the historical and political thinking but it is clear that differences remain. In both cases the goals and achievements of imperial rule are seen in the establishment of peace, the safeguarding of law and order, the administration of justice, and the spread of culture and civilization in the world. In addition, there is in both cases an overarching cosmic scheme. On the other hand, in Rome one observes a continuing interest in and appreciation of war and military achievement that have no equivalents in China.

The last section of the article focuses on the roles attributed to specific "Others," especially the "barbarians." On both sides attitudes vary. In China one observes an ongoing discussion of policies to be undertaken toward the barbarians, which, in turn, rubbed off on the historians, whose attitudes ranged from realism paired with occasional sympathy to resolute distancing from those regarded as inimical to the "great peace" (taiping 太平). In Rome there is a tension between feelings of superiority-disdain for uncivilized groups who need Roman rule to participate in a civilized life — and a vague fear that it might be exactly the absence of culture and civilization that makes the barbarians a threat to the empire.

We want to conclude with expressing our hope that the presentation of these three articles will contribute to stimulating further comparative studies of China and the West and thus to promoting the mutual understanding between these two spheres-so strikingly equal in both their cultural and historical wealth and in their significance for the world's future.

TUEBINGEN UNIVERSITY Tuebingen, Germany TECHNISCHE UNIVERSITÄT DRESDEN

Dresden, Germany

\section{ENDNOTE}

1. Lüshi Chunqiu《呂氏春秋》, 4.6. 